\title{
Vibration Effects of Nonclassically Damped Building-Piping Systems Subjected to Extreme Loads
}

\author{
YongHee Ryu, ${ }^{1}$ WooYoung Jung, ${ }^{2}$ and BuSeog Ju' \\ ${ }^{1}$ Department of Civil Engineering, North Carolina State University, Raleigh, NC 27695, USA \\ ${ }^{2}$ Department of Civil Engineering, Gangneung-Wonju National University, Gangneung 210-702, Republic of Korea \\ Correspondence should be addressed to BuSeog Ju; bju2@ncsu.edu
}

Received 22 September 2015; Accepted 30 December 2015

Academic Editor: Salvatore Russo

Copyright (c) 2016 YongHee Ryu et al. This is an open access article distributed under the Creative Commons Attribution License, which permits unrestricted use, distribution, and reproduction in any medium, provided the original work is properly cited.

\begin{abstract}
Piping leakage can occur at T-joint, elbows, valves, or nozzles in nuclear power plants and nonnuclear power plants such as petrochemical plants when subjected to extreme loads and such leakage of piping systems can also lead to fire or explosion. For example, leakage of sodium, toxic gases, or nitrogen in hospitals can cause man-made hazards. The primary objective of this research is to understand the vibration effects due to classical/nonclassical damping with building-piping systems under extreme loads. The current evaluation employed finite-element analysis to calculate the effects of the responses of classically and nonclassically damped building-piping systems. Classical and nonclassical damping matrices for a coupled primary-secondary system were developed based on the Rayleigh equation. A total of 10 selected ground motions were applied to single degree of freedom (SDOF) primarySDOF secondary (2-DOF coupled) systems in which the ratios of the natural frequencies between the primary and secondary systems ranged between 0.9 and 1.1. It revealed that the vibration effect of nonclassical damping was significant where the natural frequencies of the two systems were nearly tuned. For piping-material nonlinearity, the effects of nonclassical damping on the result forces of piping systems were not significantly different from those of classical damping.
\end{abstract}

\section{Introduction}

The vibration of a piping system is significantly influenced by the building in which it is installed, owing to the fact that, typically for such systems, the secondary structure is coupled with the primary structure. The individual components of piping systems and their overall structural integrity are critical to risk management and the continued safe operation of critical facilities such as hospitals and nuclear power plants during extreme loads such as blasts or earthquakes, most especially so as to avoid potential shutdowns. As seen in the recent sequence of events at the Fukushima Daiichi Nuclear power plant in 2011, keeping the core of the reactor cool by long-duration circulation of coolants is a necessity, even after a plant has been shut down due to an earthquake. A piping-system or individual-component failure can result in the loss of the capacity to circulate coolant, which, in turn, can increase the risk of the release of radioactivity. Furthermore, leakage of liquid coolant such as sodium in fast breeder reactor can trigger the internal fires and leakage of oxygen or other gases initiated from piping systems in a hospital can result in fire hazards or explosions [1]. For a typical medium-sized hospital, nonstructural components account for fully $85 \%$ of the total construction cost (structural components: 15\%), of which portion mechanical, electrical, and piping systems make up 35\%, as illustrated in Figure 1 [2]. It has been reported that nonstructural damage, and its results, is the cause of approximately $\$ 6.3$ billion worth of economic loss [3]. Consequently, many engineers have recognized the significance of nonstructural components and the importance of ensuring that they remain operational, functional, and safe after an earthquake.

In the past, calculating the structural response of nonclassically damped systems using uncoupled primary and secondary modal properties was more convenient than calculating the response using completely coupled primarysecondary systems, for example, the studies of the uncoupled primary and secondary systems conducted to evaluate the 


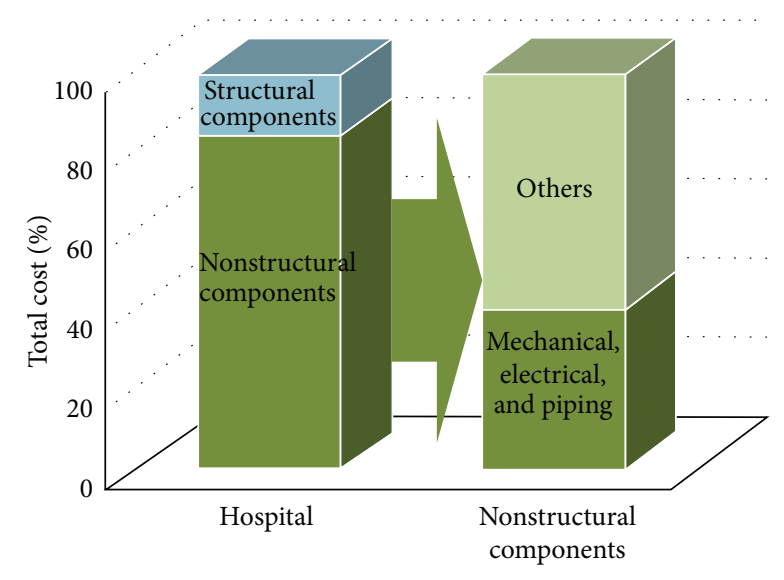

Figure 1: Construction costs of medium-sized hospital building.

response of nonclassically damped systems using response spectrum at the base of a primary structure $[4,5]$. The assumptions made (e.g., representation of ground motion using Gaussian process models) in developing their formulations, however, led to inaccurate outputs in the lowor high-frequency range. Gupta [6] pointed out that the calculated vibrations of a coupled primary-secondary system were more comprehensive and accurate than those obtained from uncoupled systems. Moreover, Gupta [7] demonstrated that the effect of nonclassical damping is significant when uncoupled systems are (nearly) tuned and when the modal mass ratios are sufficiently small. Furthermore, in recent years, many researchers have recognized the need to control the excessive behavior under seismic ground motions, in order to reduce the seismic damage or system drift of structural and nonstructural components [8-13].

Consequently, this paper reports the results of an evaluation of the vibrations of classical and nonclassical damping for coupled primary-secondary systems including material nonlinearity. Finite-element building-piping models derived from the Open System for Earthquake Engineering Simulation (OpenSees) [14] were used to carry out the Rayleigh equation to develop classical and nonclassical damping matrices for a 2-DOF coupled primary-secondary system. A total of 10 ground motions originally proposed by the ATC63 project (publication: FEMA P695 [15]) as extreme loading conditions were selected for this study. A numerical model was developed for direct-integration time-history analyses of each ground motion case. The piping models included the effects of piping nonlinearity due to piping components' nonlinear behaviors. The effect of the mass ratio between building and piping systems also was studied.

\section{Analysis of Primary and Secondary Systems}

Piping systems installed in typical hospitals or office buildings are comprised of main-pipe lines, piping branches, and supports. An equivalent 2-degree of freedom (DOF) coupled (SDOF primary-SDOF secondary) system is shown in Figure 2. The diagram represents the piping subsystem in a building in which the mass of the frame is assumed to

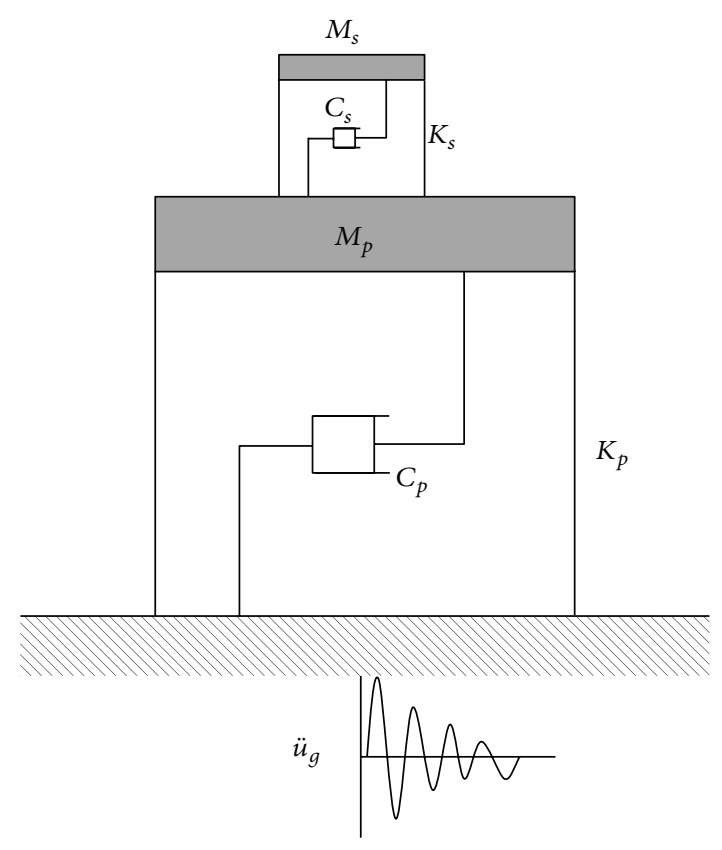

FIGURE 2: SDOF building-SDOF piping system.

be concentrated at the floor levels or main piping lines, and the floor beams or branches are assumed to be rigid, with the story stiffness provided by the flexure of the columns or piping supports. The typical values of the modal mass ratios in actual building-piping systems are on the order of 0.0001 or lower [16].

2.1. Equation of Motion for Coupled System. The equation of motion for an N-DOF coupled primary-secondary system can be written as follows:

$$
M \ddot{U}+C \dot{U}+K U=-M \ddot{u}_{g}(t),
$$

where $M$ is the mass matrix, $C$ is the damping matrix, $K$ is the stiffness matrix, $U$ is the displacement vector with respect to the fixed base, and $u_{g}$ is the ground acceleration.

These matrices and vectors can be expressed in terms of the matrices and vectors of the primary and secondary systems:

$$
\begin{aligned}
M & =\left[\begin{array}{cc}
M_{p} & 0 \\
0 & M_{s}
\end{array}\right], \\
C & =\left[\begin{array}{cc}
C_{p}+C_{p}^{s} & C_{p s} \\
C_{s p} & C_{s}
\end{array}\right], \\
K & =\left[\begin{array}{cc}
K_{p}+K_{p}^{s} & K_{p s} \\
K_{s p} & K_{s}
\end{array}\right], \\
U & =\left\{\begin{array}{l}
U_{p} \\
U_{s}
\end{array}\right\},
\end{aligned}
$$

where those matrices and vectors are denoted by subscripts $p$ and $s$, respectively, and the matrices $K_{p}^{s}$ and $C_{p}^{s}$ are the 


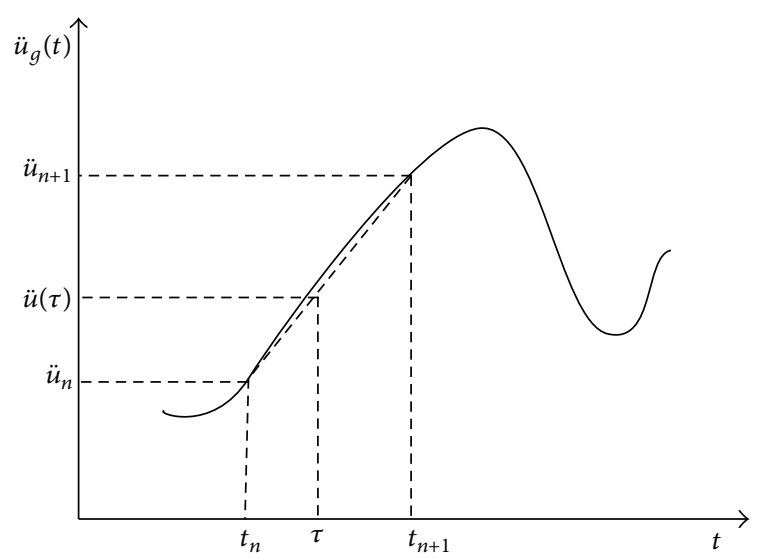

FIGURE 3: Linear representation of acceleration $\ddot{u}(\tau)$.

stiffness and damping contributions of the secondary system to the connected degrees of freedom in the primary system.

Direct integration of the equation of motion into the time-history analysis enables calculation of the system responses at discrete, usually equally apportioned intervals of time. As seen in (1), displacement, velocity, and acceleration are the basic computation parameters for determination of structural response. The integration algorithms are based on appropriate expressions selected for their relation of the response parameters at the given intervals of time to their historic values.

If the acceleration function in terms of force is represented by a series of straight lines, precise formulations for integration of the equation of motion can be developed in a linear system. With due consideration of the time-dependent acceleration $\ddot{u}(\tau)$, the variation of acceleration with time can reasonably be assumed to be linear (shown by the dashed line in Figure 3) when a sufficiently small interval of time $\Delta t$ is used. With the origin location at time $\tau, \ddot{u}(\tau)$ can be written as follows:

$$
\ddot{u}(\tau)=\ddot{u}_{n}+\frac{\ddot{u}_{n+1}-\ddot{u}_{n}}{t_{n+1}-t_{n}} \tau \text {. }
$$

Using this equation's acceleration function in terms of force, the equation of motion for an N-DOF coupled primarysecondary system can be solved.

2.2. Classical and Nonclassical Damping Matrices. The response of the primary system is dominated by the firstmode frequency of the 2-DOF coupled system, and the response of the secondary system is dominated by the second-mode frequency. Therefore, a classical damping matrix for a 2-DOF coupled system can be evaluated using the Rayleigh equation:

$$
\left[C_{\mathrm{cl}}\right]=\alpha\left[\begin{array}{cc}
M_{p} & 0 \\
0 & M_{s}
\end{array}\right]+\beta\left[\begin{array}{cc}
K_{p}+K_{s} & -K_{s} \\
-K_{s} & K_{s}
\end{array}\right],
$$

where

$$
\begin{aligned}
& \alpha=\frac{2 \omega_{i} \omega_{j}}{\omega_{j}^{2}-\omega_{i}^{2}}\left(\omega_{j} \xi_{p}-\omega_{i} \xi_{s}\right), \\
& \beta=\frac{2}{\omega_{j}^{2}-\omega_{i}^{2}}\left(\omega_{j} \xi_{s}-\omega_{i} \xi_{p}\right) .
\end{aligned}
$$

The transformed damping matrix $\bar{C}$ for the coupled system is

$$
\bar{C}=\phi^{T} C \phi .
$$

Using (4) to (6), the transformed damping matrix $\overline{C_{\mathrm{cl}}}$ for a 2-DOF coupled system is always classical, which is to say, the off-diagonal terms are zeros. The nonclassical damping matrix for a 2-DOF coupled system also can be evaluated using the Rayleigh equation

$$
\begin{aligned}
& {\left[C_{p}\right]=\alpha_{p}\left[\begin{array}{cc}
M_{p} & 0 \\
0 & 0
\end{array}\right]+\beta_{p}\left[\begin{array}{cc}
K_{p} & 0 \\
0 & 0
\end{array}\right],} \\
& {\left[C_{s}\right]=\alpha_{s}\left[\begin{array}{cc}
0 & 0 \\
0 & M_{s}
\end{array}\right]+\beta_{s}\left[\begin{array}{cc}
K_{s} & -K_{s} \\
-K_{s} & K_{s}
\end{array}\right],} \\
& {\left[C_{\mathrm{nc}}\right]=\left[C_{p}\right]+\left[C_{s}\right],}
\end{aligned}
$$

where $\alpha_{p}$ and $\beta_{s}$ are calculated as

$$
\begin{aligned}
& \alpha_{p}=\frac{2 \omega_{i} \omega_{j}}{\omega_{j}^{2}-\omega_{i}^{2}}\left(\omega_{j} \xi_{p}-\omega_{i} \xi_{p}\right), \\
& \beta_{p}=\frac{2}{\omega_{j}^{2}-\omega_{i}^{2}}\left(\omega_{j} \xi_{p}-\omega_{i} \xi_{p}\right), \\
& \alpha_{s}=\frac{2 \omega_{i} \omega_{j}}{\omega_{j}^{2}-\omega_{i}^{2}}\left(\omega_{j} \xi_{s}-\omega_{i} \xi_{s}\right), \\
& \beta_{s}=\frac{2}{\omega_{j}^{2}-\omega_{i}^{2}}\left(\omega_{j} \xi_{s}-\omega_{i} \xi_{s}\right) .
\end{aligned}
$$

Since the damping ratio between the primary system and the secondary system is not the same, the transformed damping matrix $\overline{C_{n c}}$ is nonclassical, or, in other words, the off-diagonal terms are nonzero.

\section{Ground Motion and Response Spectra}

In order to evaluate classically and nonclassically damped coupled primary-secondary systems, a total of 10 ground motions originally proposed by the ATC- 63 project, published as FEMA P695 [15], were selected in this study. The records correspond to earthquakes resulting from a variety of fault mechanisms including normal, reverse, and strikeslip fault. The local condition for each record was considered to be either site class $\mathrm{C}$ or $\mathrm{D}$, and no more than two records were selected for a single earthquake. Table 1 lists the detailed characteristics of the ground motion records. As is indicated, the data were recorded in the US, Turkey, Iran, 
TABLE 1: Details of selected ground motions.

\begin{tabular}{|c|c|c|c|c|c|}
\hline Number & Date & Event & Location & $\begin{array}{c}\text { Magnitude } \\
\left(M_{w}\right)\end{array}$ & $\operatorname{Dt}(\mathrm{s})$ \\
\hline 1 & $\begin{array}{l}08 / 17 \\
1999\end{array}$ & Kocaeli & $\begin{array}{l}\text { Arcelik, } \\
\text { Turkey }\end{array}$ & 7.5 & 0.01 \\
\hline 2 & $\begin{array}{l}10 / 16 \\
1999\end{array}$ & Hector Mine & $\begin{array}{l}\text { Hector, } \\
\text { USA }\end{array}$ & 7.1 & 0.01 \\
\hline 3 & $\begin{array}{l}10 / 15 \\
1979\end{array}$ & $\begin{array}{l}\text { Imperial } \\
\text { Valley }\end{array}$ & $\begin{array}{l}\text { Delta, } \\
\text { USA }\end{array}$ & 6.5 & 0.005 \\
\hline 4 & $\begin{array}{l}08 / 17 \\
1999\end{array}$ & Kocaeli & $\begin{array}{l}\text { Duzce, } \\
\text { Turkey }\end{array}$ & 7.5 & 0.01 \\
\hline 5 & $\begin{array}{c}09 / 20 \\
1999\end{array}$ & Chi-Chi & $\begin{array}{l}\text { Tcu045, } \\
\text { Taiwan }\end{array}$ & 7.6 & 0.02 \\
\hline 6 & $\begin{array}{c}06 / 20 \\
1990\end{array}$ & Manjil & $\begin{array}{c}\text { Manjil, } \\
\text { Iran }\end{array}$ & 7.4 & 0.005 \\
\hline 7 & $\begin{array}{l}01 / 17 \\
1994\end{array}$ & Northridge & $\begin{array}{c}\text { Beverly Hills, } \\
\text { USA }\end{array}$ & 6.7 & 0.01 \\
\hline 8 & $\begin{array}{c}04 / 25 \\
1992\end{array}$ & $\begin{array}{c}\text { Cape } \\
\text { Mendocino }\end{array}$ & $\begin{array}{c}\text { Rio Dell } \\
\text { Overpass Ff, } \\
\text { USA }\end{array}$ & 7.0 & 0.005 \\
\hline 9 & $\begin{array}{l}10 / 18 \\
1989\end{array}$ & Loma Prieta & $\begin{array}{c}\text { Gilroy Array, } \\
\text { USA }\end{array}$ & 6.9 & 0.005 \\
\hline 10 & $\begin{array}{l}11 / 12 \\
1999\end{array}$ & Duzce & $\begin{array}{l}\text { Bolu, } \\
\text { Turkey }\end{array}$ & 7.1 & 0.01 \\
\hline
\end{tabular}

and Taiwan. The earthquake magnitude was greater than 6.0 $M_{w}$ in every case, and the range of peak ground accelerations (PGA) was $0.210 \mathrm{~g}-0.822 \mathrm{~g}$. To investigate the effect of the frequency tunings between two systems, linear and nonlinear time-history analyses were conducted using building-piping models subjected to the 10 different ground motions. For that purpose, the ground motions were first normalized to a given value of PGA (see Figure 4), so that the effect of the tuning for the different ground motions could be indicated more clearly. Figure 5 plots the response spectra of the total ground motions.

\section{Classical and Nonclassical Damping in Coupled System}

Linear and nonlinear direct-integration time-history analyses were performed using SDOF primary-SDOF secondary (2DOF coupled) finite-element models subjected to each normalized ground motion. The different ratios of the natural frequencies or masses between the primary and secondary systems were considered.

4.1. Response Using Classical or Nonclassical Damping Matrix. For the uncoupled primary and secondary systems, the masses $M_{p}=90.7 \mathrm{~kg}$ and $M_{s}=0.00907 \mathrm{~kg}$, respectively, were considered. The damping ratios for the primary and secondary systems were $\xi_{p}=5 \%$ and $\xi_{s}=2 \%$, respectively. In general, the $5 \%$ damping ratio represents concrete material, and the $2 \%$ damping ratio, steel material. To represent the
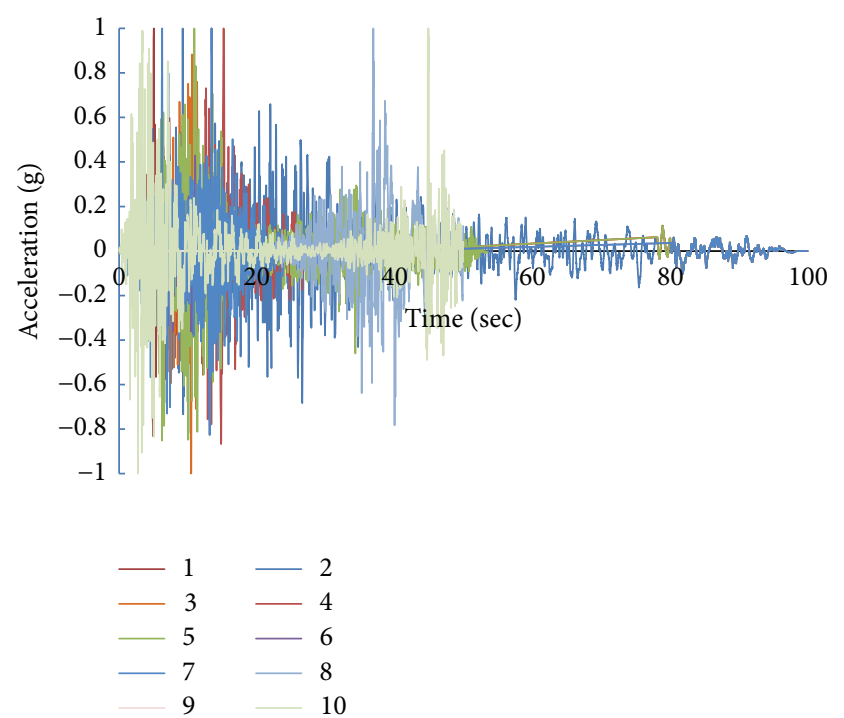

FIgURE 4: Normalized ground motions.

respective stiffness of the primary and secondary systems, $K_{p}$ $=10,205 \mathrm{~N} / \mathrm{mm}$ and $K_{s}=0.827-1.235 \mathrm{~N} / \mathrm{mm}$ were applied, and the frequencies were nearly tuned with $f_{p}=2.717 \mathrm{~Hz}$ and $f_{s}=2.978-2.988 \mathrm{~Hz}$. To further illustrate the significance of nonclassical damping, a parametric study was conducted using SDOF primary-SDOF secondary (2-DOF coupled) systems and varying the tuning between their frequencies within the 0.9-1.1 range. Figure 6 shows the differences in the 


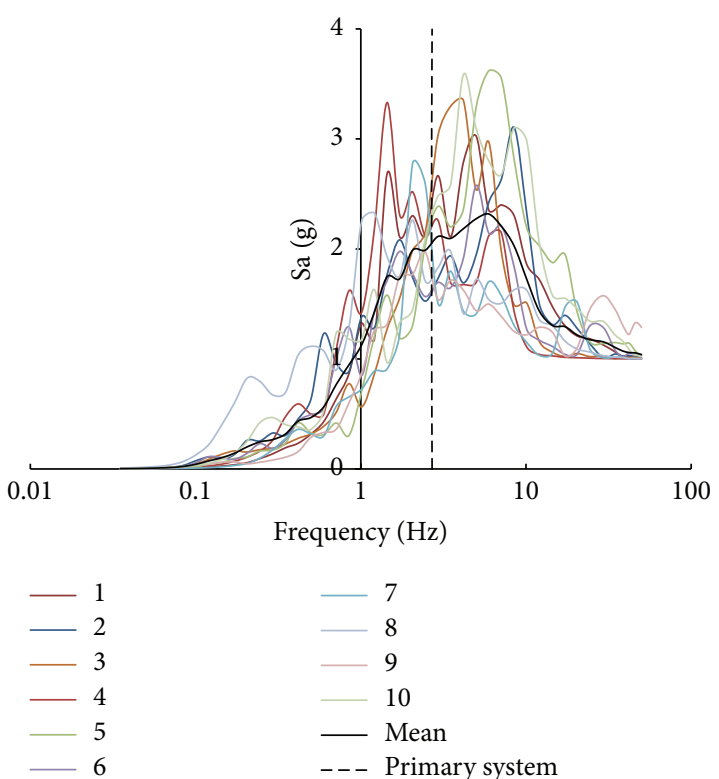

FIGURE 5: Response spectra.

TABLE 2: Result forces for secondary system in case of $f_{s} / f_{p}=1.0$.

\begin{tabular}{lc}
\hline Number & Force $(\mathrm{N})$ \\
\hline 1 & 552.92 \\
2 & 448.71 \\
3 & 1117.07 \\
4 & 424.80 \\
5 & 758.64 \\
6 & 341.06 \\
7 & 520.78 \\
8 & 350.02 \\
9 & 470.27 \\
10 & 926.48 \\
\hline
\end{tabular}

secondary-system result forces obtained from the nonclassical and classical damping matrices for different frequencyratio values: specifically, the ratios of secondary to primary system frequency for each ground motion. As seen in the figure, the effect of nonclassical damping was significant only in the systems that had nearly tuned modes. Table 2 lists the result forces for the secondary systems subjected to ground motions.

4.2. Responses of Two Systems Including Material Nonlinearity. A nonlinear finite-element model for a piping system was developed using OpenSees [17] and a hysteretic material model. The hysteretic behavior of the piping component was characterized by the basic parameters: yield strength $F_{y}$, initial stiffness $k_{1}$, and hardening stiffness $k_{2}$, as shown in Figure 7, and elasticbeamcolumn element given in Table 3 was also used in OpenSees. Typically, the material property of the piping systems derived from the yield strength was defined by its initial stiffness $k_{1}$, listed in Table 4 . Figure 8 plots the result forces of the vibrations for classically or

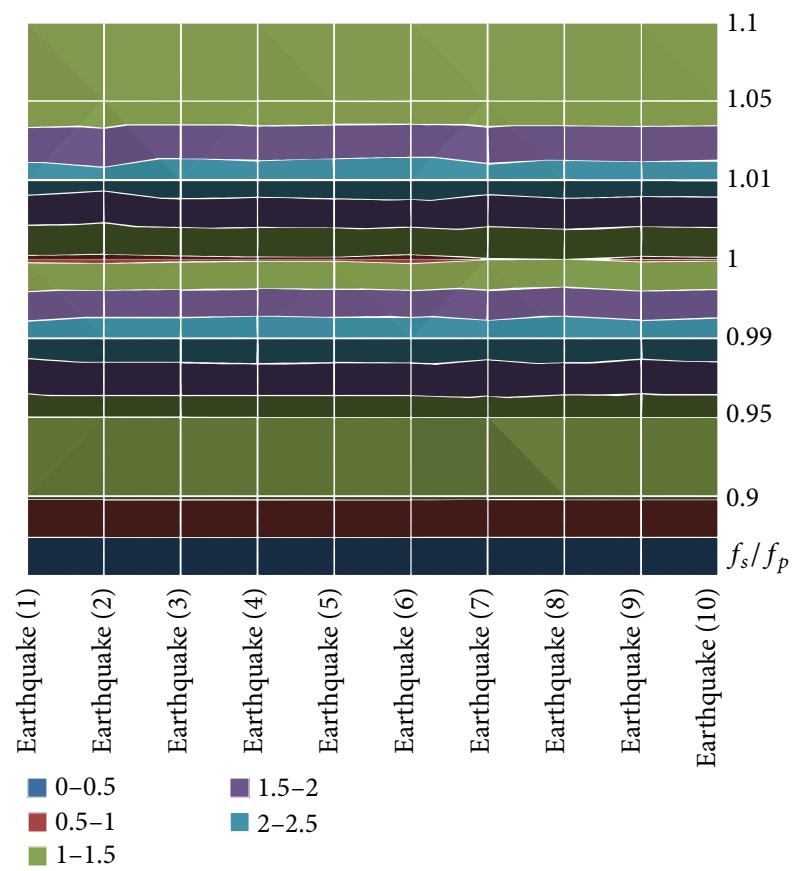

Figure 6: Differences in scale of 2-DOF coupled system.

nonclassically damped coupled primary-secondary systems including piping-material nonlinearity. The PGA for the first ground motion, as multiplied by 0.1 , was selected for this study. As indicated in the figure, the result forces in the range of $f_{s} / f_{p}<1.05$, between the classically and nonclassically damped systems, did not show significant differences using the nonlinear piping system. Even if the $f_{s} / f_{p}$ was greater than 1.00, the result forces between the classically and nonclassically damped systems again showed no significant differences. This was due to the fact that the piping system still remained in the elastic range (see Figure 7). It should be noted that the displacements of the piping system in the nonlinear range showed differences due to the nature of the nonlinear material behavior, even when the result forces with respect to the piping nonlinearity were very close.

4.3. Effect of Mass Ratios for Nonlinear Piping Systems. Gupta (1999) earlier found that the effect of nonclassical damping was significant when the modal mass ratios of coupled primary-secondary systems were sufficiently small and those systems remained in the linear elastic range. Figure 9 shows the differences between nonclassical damped systems and classically damped systems for a linear buildingpiping system as well as a linear building system and a nonlinear piping system. The effect of nonclassical damping was significant when the mass ratios between the primarysecondary systems were on the order of 0.0001 or lower. However, if the piping system was in the nonlinear range, the differences in the result forces were significantly reduced. Next, the vibration effect of between classically/nonclassically damped coupled primary-secondary systems subjected to ground motions will be discussed. 


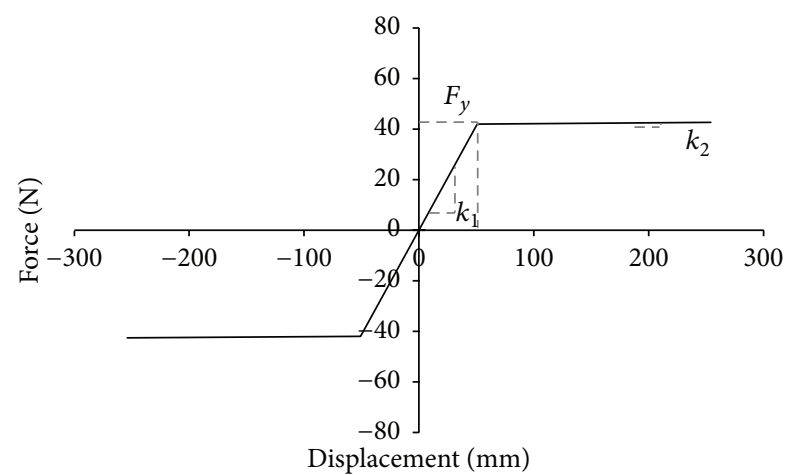

(a) $f_{s} / f_{p}=0.9$

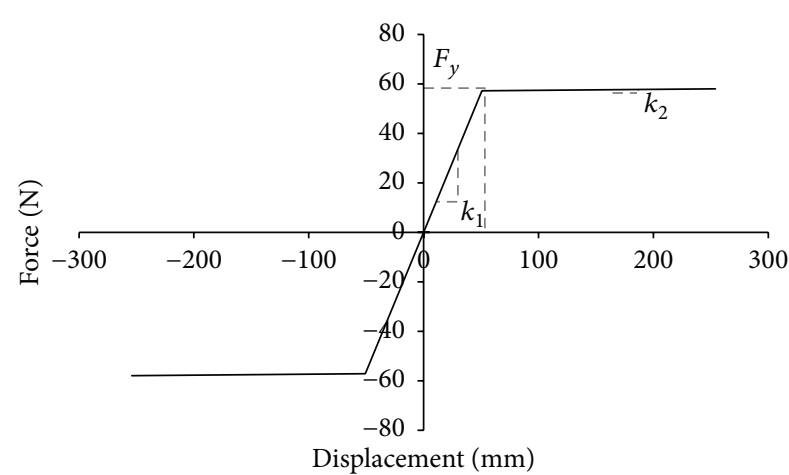

(b) $f_{s} / f_{p}=1.05$

FIGURE 7: Nonlinear material behavior for piping system.

TABLE 3: Definition of the elasticbeamcolumn element parameters in OpenSees (after Mazzoni et al., 2006 [17]).

\begin{tabular}{lc}
\hline Parameters & Definitions \\
\hline $\begin{array}{l}\text { \$eleTag } \\
\$ i \text { Node } \$ \text { Node }\end{array}$ & Unique element object tag \\
$\$ A$ & End nodes \\
$\$ E$ & Cross-sectional area of element \\
$\$ G$ & Young's modulus \\
$\$ J$ & Shear modulus \\
$\$ I z$ & Torsional moment of inertia of cross section \\
$\$ I y$ & Second moment of area about the local $z$-axis \\
$\$$ transfTag & Second moment of area about the local $y$-axis \\
\hline
\end{tabular}

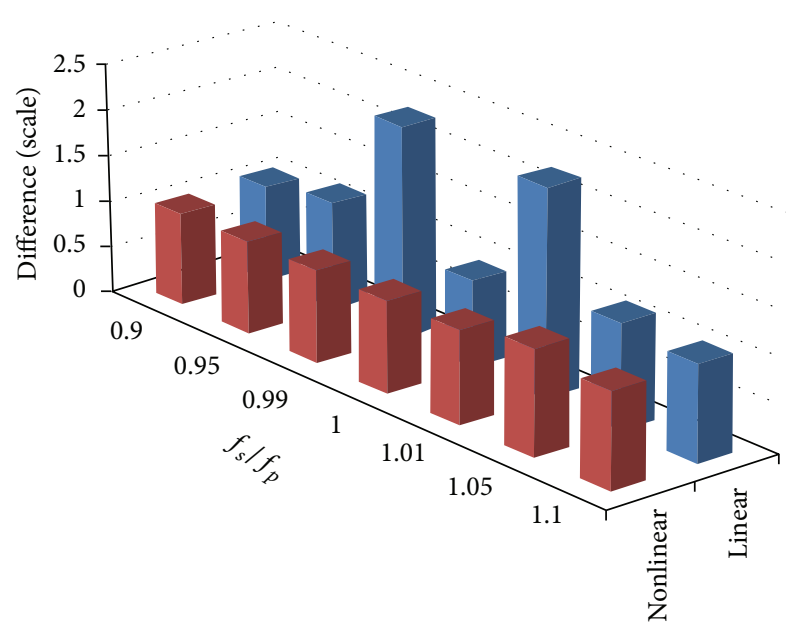

FIGURE 8: Linear versus nonlinear responses of piping system.

\section{Vibration Attenuation of Building-Piping System under Seismic Ground Motions}

For vibration control of the building-piping system, the relative effectiveness of the classical and nonclassical damping system was considered in this study. In particular, five simulations corresponding to the different frequency ratio between the systems were carried out to measure the

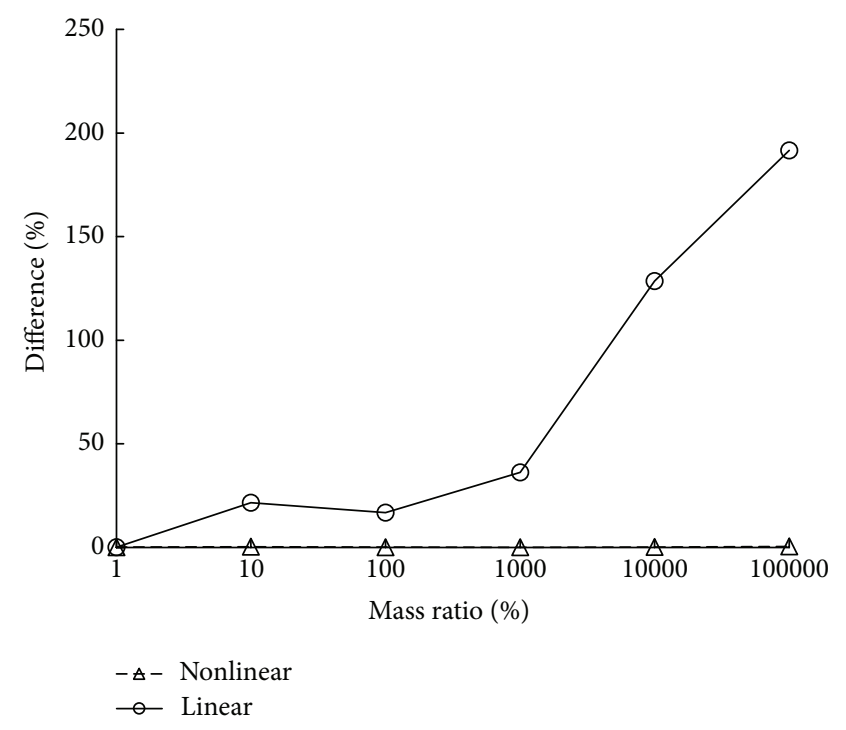

FIGURE 9: Difference between linear and nonlinear models with respect to mass ratio.

acceleration time histories at the top floor of the system. A vibration comparison between classical and nonclassical damped systems conducted in OpenSees was described in Figure 10. Also, it showed the quantitative comparison of the acceleration capacities of the systems. It can be seen 


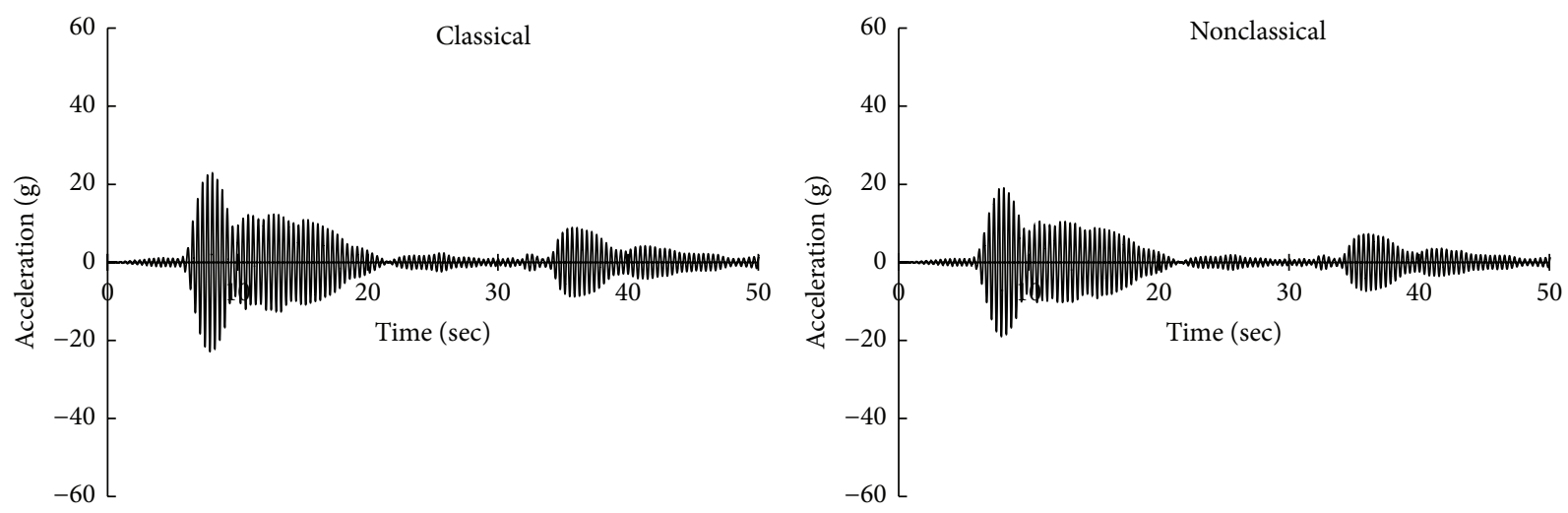

(a) $f_{s} / f_{p}=0.95$
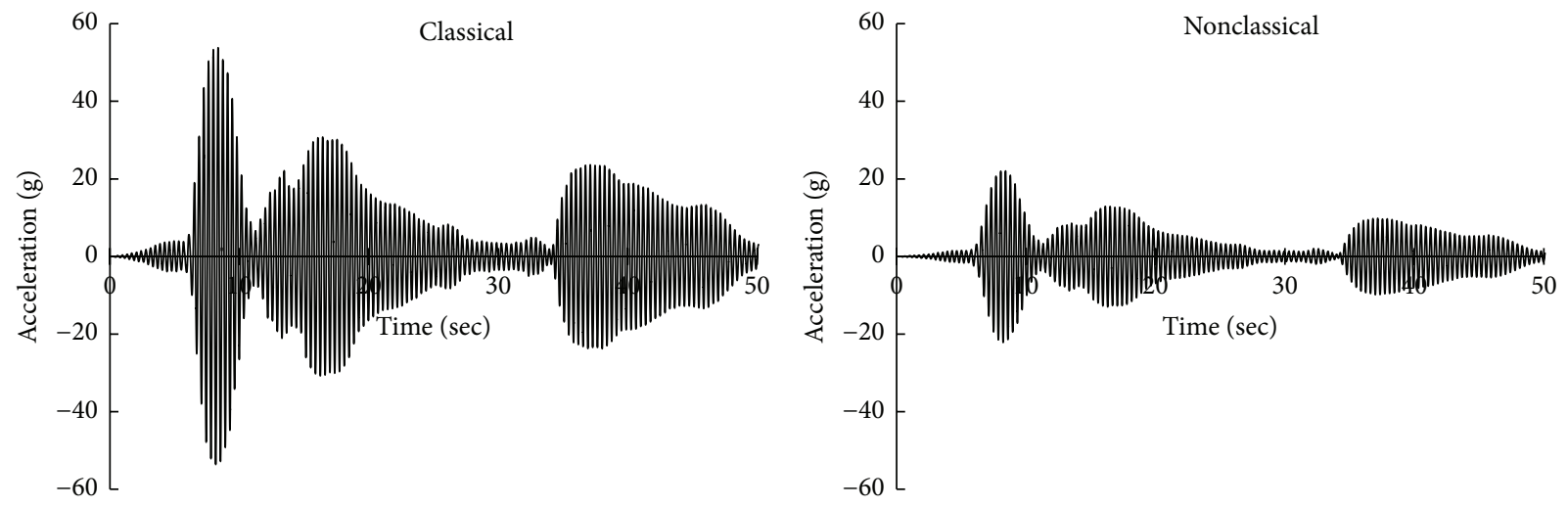

(b) $f_{s} / f_{p}=0.99$
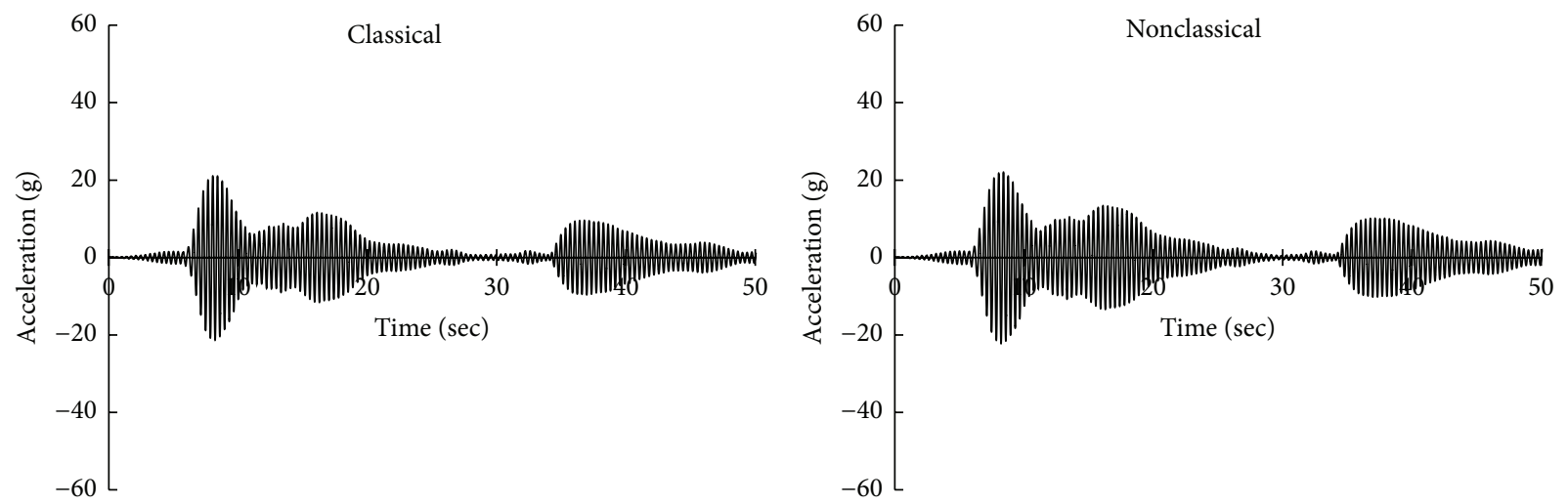

(c) $f_{s} / f_{p}=1.00$
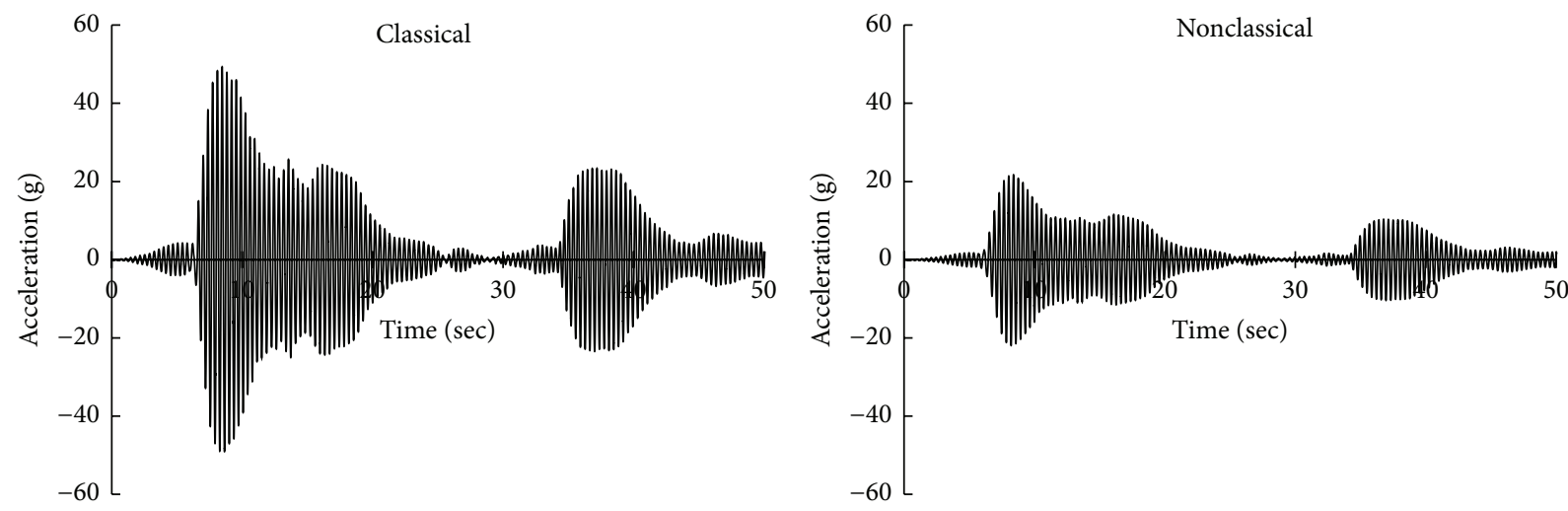

(d) $f_{s} / f_{p}=1.01$

Figure 10: Continued. 

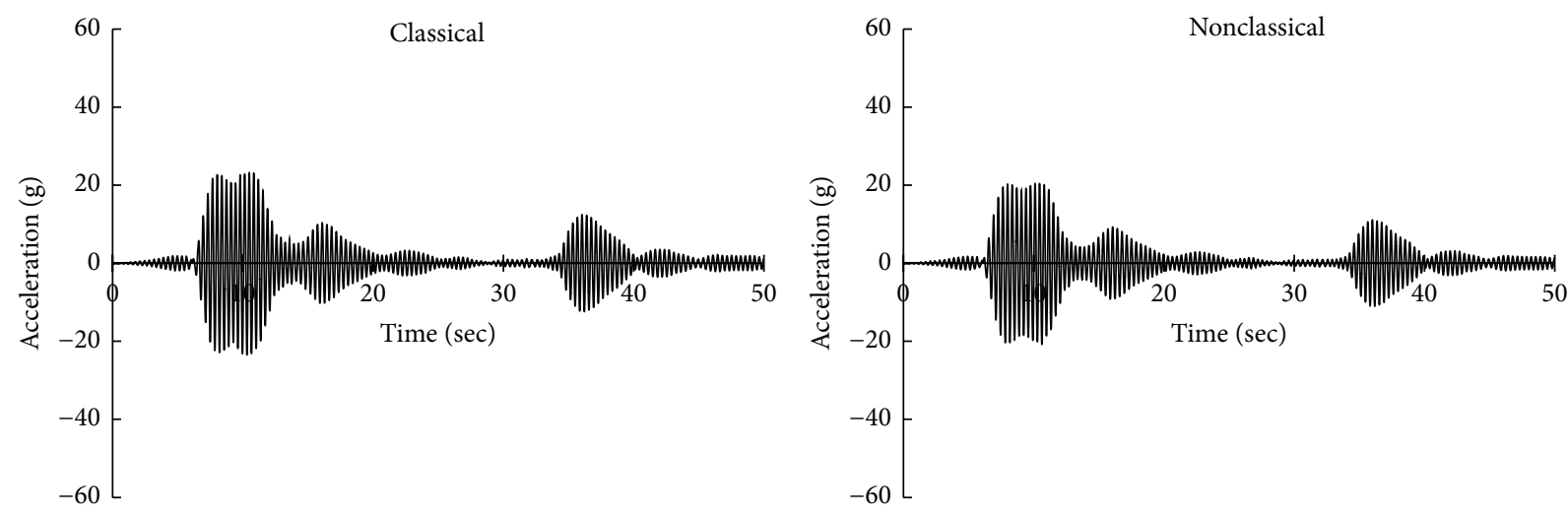

(e) $f_{s} / f_{p}=1.05$

Figure 10: Acceleration time histories with different frequencies in classically and nonclassically damped coupled building-piping systems.

TABLE 4: The parameters of coupled building-piping systems.

\begin{tabular}{lcc}
\hline Parameter & $f_{s} / f_{p}=0.9$ & $f_{s} / f_{p}=1.05$ \\
\hline$F_{y}$ & $42 \mathrm{~N}$ & $57 \mathrm{~N}$ \\
$k_{1}$ & $826.61 \mathrm{~N} / \mathrm{m}$ & $1125.11 \mathrm{~N} / \mathrm{m}$ \\
$k_{2}$ & $8.26 \mathrm{~N} / \mathrm{m}$ & $11.25 \mathrm{~N} / \mathrm{m}$ \\
\hline
\end{tabular}

that there was a similar manner in all of the acceleration time histories: nonclassical damped building-piping system was more conservative than classical coupled building-piping system, in terms of reducing the floor accelerations through the ground acceleration using the 1999 Chi-Chi earthquake. Furthermore, the nonclassical damped system showed the vibration attenuation about $20 \%$ with $0.95,0.99$, and 1.05 frequency ratios. In terms of frequency ratios-0.99 and 1.01, however, the vibration attenuation was significantly influenced by nonzero off-diagonal term, resulting in a decrease of more than 50\%. Consequently, the vibration of the coupled building-piping system was sensitive to the mechanical properties such as mass and stiffness ratio of the primary and secondary system.

\section{Conclusions}

The present study evaluated the effects of the seismic responses of classically and nonclassically damped coupled primary-secondary piping systems, including nonlinearity behavior. A finite-element building-piping model using OpenSees was employed to develop, using the Rayleigh equation, classical and nonclassical damping matrices for a 2-DOF coupled primary-secondary system. A total of 10 selected ground motions were applied to SDOF primarySDOF secondary (2-DOF coupled) systems in which the ratios of the natural frequencies between the primary and secondary systems ranged between 0.9 and 1.1. Linear and nonlinear direct-integration time-history analyses were performed for each ground motion case. It was shown that the effect of nonclassical damping was significant in systems that have nearly tuned modes. For piping-material nonlinearity, the effects of nonclassical damping on the result forces of the piping system were not significantly different from those of classical damping. In fact, they were insignificant, even though the modal mass ratios were sufficiently small. However, it should be noted that, even when the result forces are very close, piping-system displacements in the nonlinear range can show differences due to the nature of nonlinear material behavior. Additionally, in the simulations using classically and nonclassically damped systems, it was interesting to find that nonzero off-diagonal term in nonclassical damping matrices was very effective to the vibration attenuation, especially, coupled building-piping system with frequency range of 0.95 to 1.05 . Also, the probabilistic risk assessment of coupled building-piping systems as the analysis of the vibration attenuation must be achieved, in order to evaluate the probability of failure with respect to material uncertainty and ground motion uncertainty using classical and nonclassical damping matrices.

\section{Conflict of Interests}

The authors declare that there is no conflict of interests regarding the publication of this paper.

\section{Acknowledgment}

This work was supported by a National Research Foundation of Korea (NRF) grant funded by the Korean government (MEST) (no. 2012-0008762).

\section{References}

[1] Y. H. Ryu, A. Gupta, B. S. Ju, and W. Y. Jung, "A framework for evaluating the probability of fire hazard due to leakage of liquid coolant in fast breeder reactor," in Proceedings of the 23rd International Conference on Structural Mechanics in Reactor Technology Conference (SMiRT '15), Manchester, UK, August 2015.

[2] FEMA 577, Risk Management Series Design Guide for Improving Hospital Safety in Earthquakes, Floods, and High Winds, Federal Emergency Management Agency, Washington, DC, USA, 2007. 
[3] C. A. Kircher, "It makes dollars and sense to improve nonstructural system performance," in Proceedings of the Seminar on Seismic Design, Performance, and Retrofit of Nonstructural Components in Critical Facilities, ATC-29-2, pp. 109-120, Newport Beach, Calif, USA, October 2003.

[4] M. P. Singh and S. L. Chu, "Stochastic considerations in seismic analysis of structures," Earthquake Engineering and Structural Dynamics, vol. 4, no. 3, pp. 295-307, 1976.

[5] R. Villavarde and N. M. Newmark, "Seismic response of light attachments to buildings," Structural Research Series no. 469, University of Illinois, Urbana, Ill, USA, 1980.

[6] A. K. Gupta, Response Spectrum Method in Seismic Analysis and Design of Structures, CRC Press, Boca Raton, Fla, USA, 1992.

[7] A. Gupta, "Significance of nonclassical damping in coupled system analysis," in Proceedings of the 15th Structural Mechanics in Reactor Technology Conference (SMiRT '99), Seoul, Republic of Korea, August 1999.

[8] K. Park, D. Kim, D. Yang, J. Daeki, I. Ha, and S. Kim, "A comparison study of conventional construction methods and outrigger damper system for the compensation of differential column shortening in high-rise buildings," International Journal of Steel Structures, vol. 10, no. 4, pp. 317-324, 2010.

[9] S. Aghajanian, H. Baghi, F. Amini, and M. Z. Samani, "Optimal control of steel structures by improved particle swarm," International Journal of Steel Structures, vol. 14, no. 2, pp. 223-230, 2014.

[10] S.-H. Oh, S.-H. Song, S.-H. Lee, and H.-J. Kim, "Seismic response of base isolating systems with U-shaped hysteretic dampers," International Journal of Steel Structures, vol. 12, no. 2, pp. 285-298, 2012.

[11] D.-H. Shin and H.-J. Kim, "Probabilistic assessment of structural seismic performance influenced by the characteristics of hysteretic energy dissipating devices," International Journal of Steel Structures, vol. 14, no. 4, pp. 697-710, 2015.

[12] C. F. Ma, Y. H. Zhang, P. Tan, and F. L. Zhou, "Seismic response of base-isolated high-rise buildings under fully nonstationary excitation," Shock and Vibration, vol. 2014, Article ID 401469, 11 pages, 2014.

[13] D. Foti, "On the seismic response of protected and unprotected middle-rise steel frames in far-field and near-field areas," Shock and Vibration, vol. 2014, Article ID 393870, 11 pages, 2014.

[14] OpenSees, "Open System for Earthquake Engineering Simulation," 2006, http://opensees.berkeley.edu/.

[15] FEMA P695, Quantification of Building Seismic Performance Factors, Federal Emergency Management Agency, Washington, DC, USA, 2009.

[16] M. K. Bose, Non-classical damping properties and modal correlation coefficient for dynamic analysis of structures [Ph.D. thesis], North Carolina State University, Raleigh, NC, USA, 2001.

[17] S. Mazzoni, F. McKenna, M. H. Scott, and G. L. Fenves, "OpenSees command language manual," 2006, http://opensees .berkeley.edu/. 


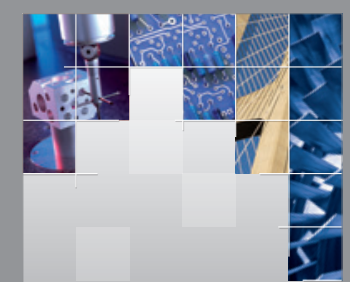

\section{Enfincering}
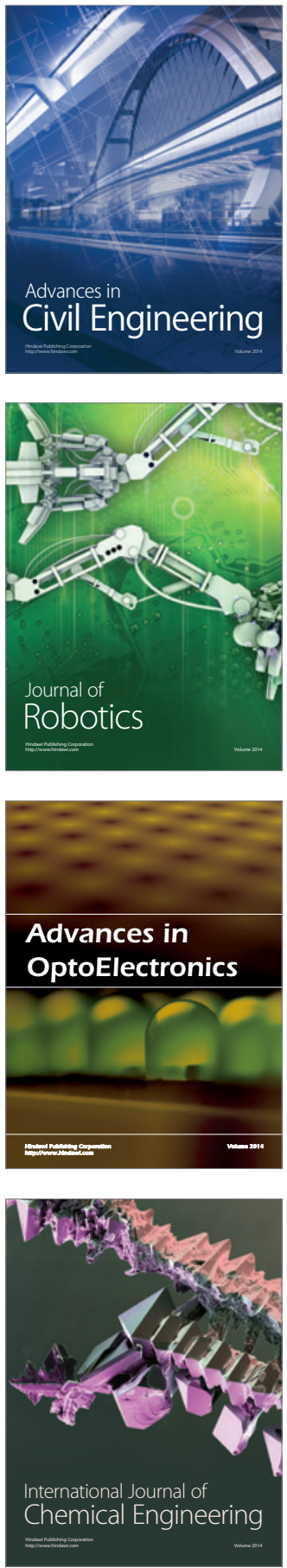

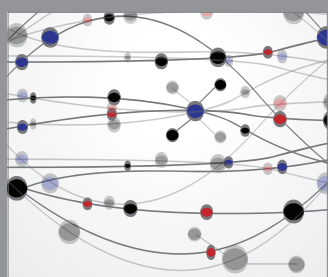

The Scientific World Journal

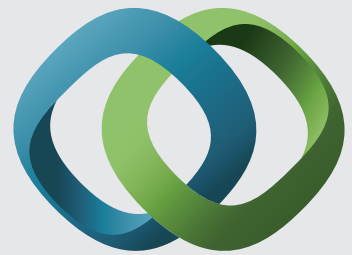

\section{Hindawi}

Submit your manuscripts at

http://www.hindawi.com
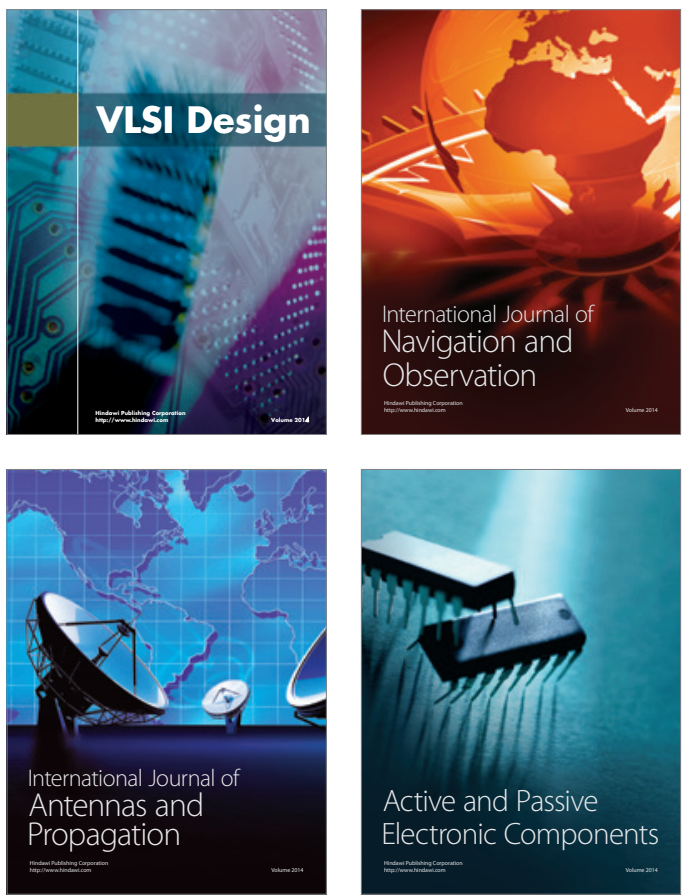
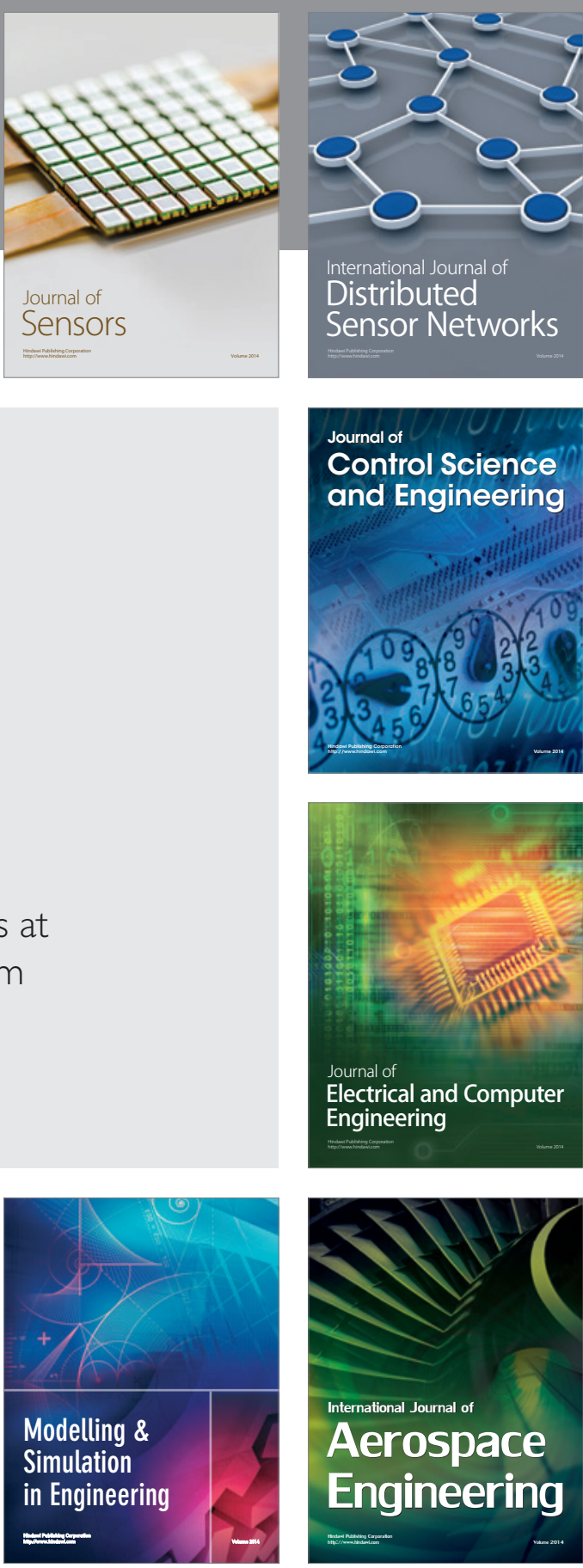

International Journal of

Distributed

Sensor Networks

Journal of

Control Science

and Engineering
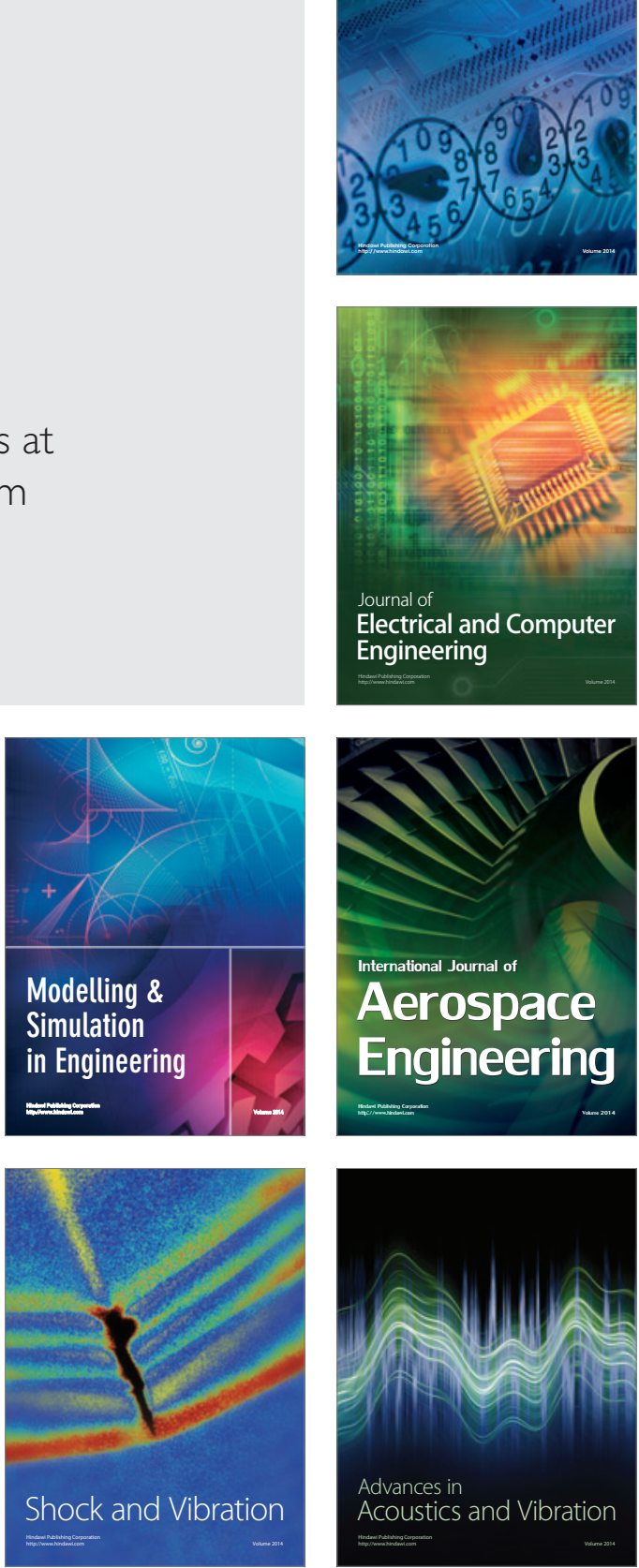